\title{
Incidence of Parenteral Nutrition-Associated Liver Disease in Infants on Prolonged Parenteral Nutrition with a Soybean-Based Lipid Emulsion: A 7-Year Experience
}

\author{
Catherine M. Crill1,2,3, Oscar R. Herrera',2*, Lindsay H. Stuart ${ }^{2}$, Michael L. Christensen ${ }^{1,2,3}$ \\ ${ }^{1}$ Department of Clinical Pharmacy and Translational Science, University of Tennessee Health Science Center, Memphis, \\ Tennessee, USA \\ ${ }^{2}$ Pharmacy Department, Le Bonheur Children's Hospital, Memphis, Tennessee, USA \\ ${ }^{3}$ Department of Pediatrics, University of Tennessee Health Science Center, Memphis, Tennessee, USA \\ Email: ${ }^{\star}$ oherrera@uthsc.edu
}

How to cite this paper: Crill, C.M., Herrera, O.R., Stuart, L.H. and Christensen, M.L. (2020) Incidence of Parenteral Nutrition-Associated Liver Disease in Infants on Prolonged Parenteral Nutrition with a Soybean-Based Lipid Emulsion: A 7-Year Experience. Food and Nutrition Sciences, 11, 899-910.

https://doi.org/10.4236/fns.2020.1110063

Received: September 22, 2020

Accepted: October 12, 2020

Published: October 15, 2020

Copyright $\odot 2020$ by author(s) and Scientific Research Publishing Inc. This work is licensed under the Creative Commons Attribution International License (CC BY 4.0).

http://creativecommons.org/licenses/by/4.0/

\begin{abstract}
Parenteral nutrition associated liver disease (PNALD) is a significant complication in infants receiving long-term parenteral nutrition (PN). Chronic administration of $\mathrm{PN}$ has been associated with its development. Our purpose is to characterize our incidence of PNALD over an extended period and identify risk factors for its development, including administration of soybean-based injectable lipid emulsions (ILEs) as we transit to novel ILEs in our practice. Infants receiving 30 days or more of PN were included. PNALD was defined as a direct bilirubin $\geq 2 \mathrm{mg} / \mathrm{dL}$. Data collected included: patient demographics, clinical and enteral feeding characteristics. Macronutrient intake was recorded using these cut-offs: glucose infusion rate (GIR) of $\leq 14 \mathrm{mg} / \mathrm{kg} / \mathrm{min}$ or above, protein doses of $\leq 3 \mathrm{~g} / \mathrm{kg} /$ day or above and lipid doses of $\leq 2 \mathrm{~g} / \mathrm{kg} / \mathrm{day}$ or above. A total of 349 infants were included, with an annual incidence of PNALD ranging between $34 \%$ - 54\%. Infants with PNALD were younger by gestation ( 27 vs. 29.5 weeks) and smaller by birthweight (900 vs. 1248 grams). Sepsis, GI disease including necrotizing enterocolitis and bowel resection were significantly associated with an increased risk for development of PNALD. PNALD infants received lower protein doses (3.0 vs $3.3 \mathrm{~g} / \mathrm{kg} /$ day, p $=0.014)$ while receiving higher GIR (11.4 vs $10.7 \mathrm{mg} / \mathrm{kg} / \mathrm{min}, \mathrm{p}=0.012)$ compared to non-PNALD infants. Low birth weight, sepsis and bowel resection remain strong indicators of risk for PNALD. No single macronutrient increased our infants' risk for PNALD. The use of newer ILEs when available should be evaluated for their impact on PNALD development.
\end{abstract}




\section{Keywords}

Parenteral Nutrition, Infants, Lipid Emulsions, Liver Disease, Cholestasis

\section{Introduction}

Parenteral nutrition (PN) plays a significant role in achieving adequate growth and development in infants unable to be fed enterally [1]. By providing nutrition intravenously, patients are able to receive: essential macronutrients including carbohydrates, lipids, and protein; micronutrients, such as vitamins, minerals, and trace elements; and electrolytes that are necessary to meet caloric needs and energy demands. PN is thought to be particularly beneficial in specific patient populations, including those with gastrointestinal (GI) disorders and/or surgical patients unable to transit to enteral nutrition postoperatively. However, $\mathrm{PN}$ is not benign, and prolonged courses can lead to increased risk of serious complications such as central line associated bloodstream infections, metabolic bone disease, and cholestasis.

Cholestasis, or parenteral nutrition associated liver disease (PNALD), is a known risk factor for patients receiving prolonged PN [2] [3]. It is estimated that the risk of PNALD increases after a patient has been on PN for greater than 14 30 days [4]. If left untreated or unresolved, PNALD has the potential to progress to more severe liver complications including hepatic fibrosis, cirrhosis, fulminant liver failure, and death [5]. There are several proposed etiologies for the development of PNALD including prematurity or immature hepatic function, lack of enteral feeding or gut stimulation, infection leading to sepsis, certain GI diagnoses including necrotizing enterocolitis (NEC), bowel resection, medications, and the duration of $\mathrm{PN}$ [6]. In addition, over-supplementation of protein, lipids, dextrose or high-calorie regimens as a whole have all been implicated as contributors to the development of PNALD [7] [8] [9]. In particular, hepatic steatosis and bile acid dysregulation seen in PNALD have been attributed to long-term administration of soybean-based lipid emulsions [10] [11]. Soybean oil is rich in omega-6 long-chain fatty acids which lead to synthesis of pro-inflammatory prostaglandins that have been linked to adverse effects on the liver [12]. In addition, vegetable oils contain phytosterols, which with increased exposure can lead to increased concentrations of such in plasma [13]. Phytosterols have been associated with impaired bile acid transport observed in PNALD [14]. Once PNALD ensues, medical teams implement changes primarily in 2 ways, by modifying PN/EN regimens or initiating medications. Agents such as cholecystokinin-octapeptide, ursodeoxycholic acid, and enteral fish oil have been studied [15] [16] [17] [18]. Among the changes in nutritional regimens likely to be done are initiation of trophic enteral feedings, cycling of PN, lipid emulsion restriction and/or substitution to lipid emulsions from other sources [19] [20] [21] [22] [23]. There is wide variability in the aforementioned therapeutic strategies among practitioners and institutions. Any one intervention has only been 
shown to have modest efficacy in resolution of PNALD, leading organizations such as the American Society of Parenteral and Enteral Nutrition (ASPEN) to give inconclusive recommendations regarding some of these interventions in patients at risk of PNALD [24].

The aim of this study was to analyze our experience in the development of PNALD in infants receiving PN. Our primary objective was to determine the incidence of PNALD in our neonate/infant population on prolonged PN with primarily a soybean-based lipid emulsion. Our secondary objectives were to identify risk factors for development of PNALD from the cohort's clinical characteristics and their nutritional regimens.

\section{Methods}

Infants who were initiated on PN during their first year of life were screened for study inclusion. Our hospital is a 255 -bed teaching facility with multiple intensive-care units (ICU). PN is implemented by a pharmacist-run consult service, in addition to standard neonatal PN solutions for non-consult patients in our neonatal ICU.

For study inclusion, patients must have been less than 12 months of age at PN initiation between January 2010 and December 2016, and received PN for at least 30 days. Patients were excluded if they were initiated on ECMO during hospitalization, had a diagnosis of primary hepatobiliary or hematologic disease per medical record, had PNALD on transfer to our institution, or developed elevated direct bilirubin while receiving phototherapy. We defined PNALD as a direct bilirubin $\geq 2 \mathrm{mg} / \mathrm{dL}$ or in its absence, a total bilirubin $\geq 4 \mathrm{mg} / \mathrm{dL}$ on 2 consecutive draws 7 days apart. The data extracted from the electronic medical record included: patient demographics (date of birth, gestational age, race, gender, etc), clinical characteristics (length of stay, diagnoses, bowel resection, and sepsis occurrence) and logistical data about their PN regimen (PN indication, PN Service consult, age at initiation and discontinuation of PN). We also recorded information on the infants' enteral feeding characteristics such as age at first enteral feeding and age when consistently fed (defined as the age when enteral feedings were ordered and no longer suspended unless for a procedure or extubation, and restarted shortly thereafter). We recorded the subject's macronutrient intake from PN and used the following cut-offs for categorizing the data: glucose infusion rate (GIR) of $\leq 14 \mathrm{mg} / \mathrm{kg} / \mathrm{min}$ or above, protein doses of $\leq 3$ $\mathrm{g} / \mathrm{kg} /$ day or above and lipid doses of $\leq 2 \mathrm{~g} / \mathrm{kg} /$ day or above. These data were collected from the PN order being provided when the pt. first had an abnormal direct bilirubin concentration or at day 7 of $\mathrm{PN}$ for those infants that did not develop PNALD. At our institution, our amino acid solution for infants is Trophamine ${ }^{\bullet}$ (BBRaun Medical Inc. Bethlehem, PA) and our only injectable lipid emulsion (ILE) available at the time was Intralipid ${ }^{\circledR}$ (Fresenius Kabi ${ }^{\circledR}$ Uppsala, Sweden). For patients that developed PNALD, further data was extracted including peak total and direct bilirubin, any medications used for the treatment of cholestasis, whether PN was cycled, and age at resolution of cholestasis if 
achieved. Data was censored at discontinuation of PN, discharge/transfer to another facility, the end of our study period $1 / 31 / 17$ or death, whichever came sooner.

Statistical analysis was performed using the SPSS 32-bit software package for Windows (release 24.0; IBM Corp.). Comparisons were made between infants who developed PNALD and those who did not. For continuous variables that were parametric, the student's t-test was utilized. Non-parametric continuous variables were analyzed using the Mann-Whitney $\mathrm{U}$ test. The chi-square test was used for categorical variables and significance was defined as a $\mathrm{p}$-value of $<0.05$. Logistic regression analyses were used to assess the predictability of certain clinical and nutritional factors in the development of PNALD on these infants. This study was approved by our local Institutional Review Board.

\section{Results}

Between January 1, 2010 and December 31, 2016 there were a total 2298 infants initiated on PN. Of those, 385 patients received PN for 30 days or more, 22 were excluded because of phototherapy, 2 had PNALD already on admission, 1 had myelodysplastic disease, and 11 developed PNALD during ECMO therapy resulting in $349(15.2 \%)$ infants included in final analysis. The primary outcome of the study was the annual incidence of PNALD that ranged between $34 \%-54 \%$ (Figure 1). Secondary outcomes included identification of clinical factors that increased the risk of PNALD and determination of macronutrient impact on the development of PNALD. For patients who developed PNALD, the average PN day at onset (D. Bili $>2 \mathrm{mg} / \mathrm{dL}$ or T. Bili $>4$ ) was $41.5 \pm 26.9$ days. The peak direct bilirubin was $5.3 \pm 4.0$ occurring at a median of 56.5 days on PN. The peak total bilirubin was $8.5 \pm 4.9 \mathrm{mg} / \mathrm{dL}$ and occurred at a median 63 days on PN.

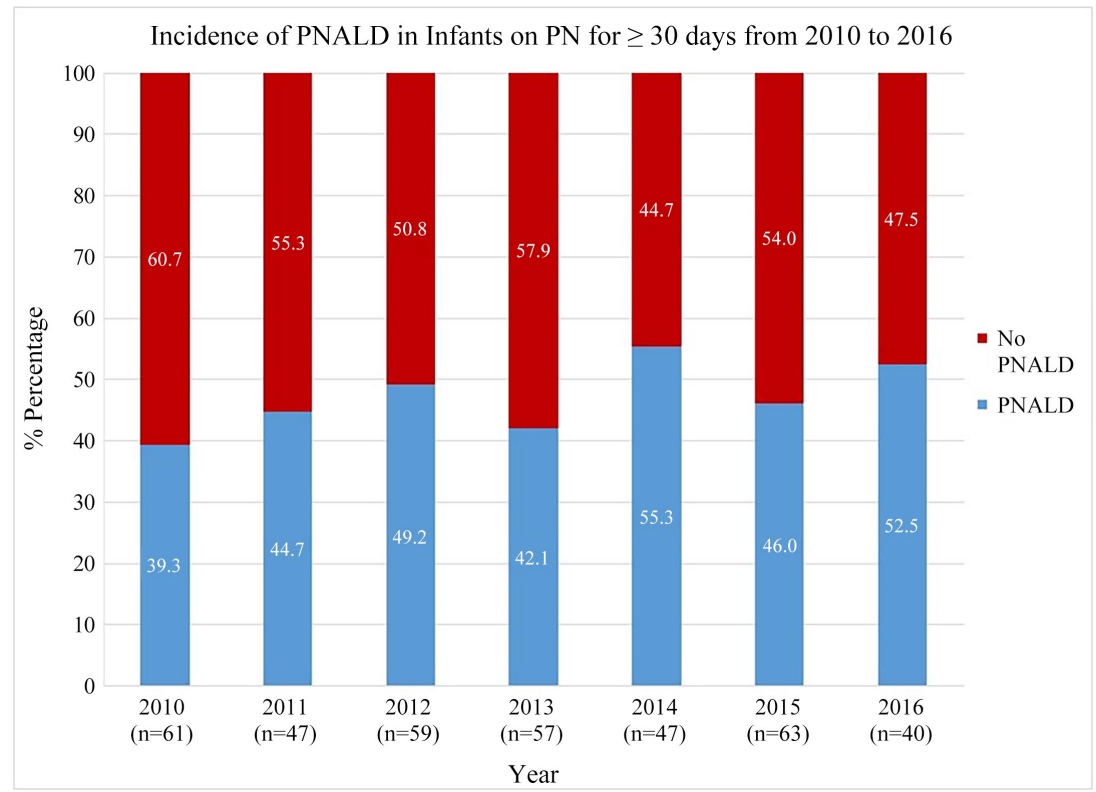

Figure 1. Incidence of Parenteral Nutrition-Associated Liver Disease (PNALD) in infants on $\mathrm{PN}$ for at least 30 days. 


\subsection{Baseline Demographics}

As shown in Table 1, patients enrolled in the study were predominantly female and African American. Gender and race/ethnicity distributions were comparable for both groups. Infants who developed PNALD were younger by gestational age, which was associated with lower birth weight and longer length of hospital stay, when compared to those that did not develop PNALD.

\subsection{Clinical Characteristics}

Sepsis, GI disease, primarily NEC and bowel resection showed statistical significance (Figure 2), $(\mathrm{p}<0.002)$. After regression analysis was conducted with all 4 factors in the model, only sepsis (O.R. 3.89; C.I 2.262 - 6.667) and bowel resection (O.R. 3.44; C.I 2.160 - 5.464) remained significant.

\subsection{Parenteral Nutrition and Feeding Characteristics}

Patients who developed PNALD had a significantly longer duration of PN and were significantly older when consistent enteral feeds were established (Table 2). Other parameters that were statistically different but likely clinically insignificant because of small differences included age PN was started, nil-per-os (NPO) duration, and age initial feeds attempted.

Analysis of macronutrient intake showed that infants with PNALD were receiving significantly less protein (9\%) and higher glucose infusion rates (6.5\%) compared to those infants that did not develop PNALD (Table 3). Lipid dose was not statistically different between the two groups. We saw no effect on the incidence of PNALD during two periods of lipid shortages where we implemented a lipid restriction protocol. Regression analyses showed that infants were more likely (O.R. 2.5, C.I 1.017 - 1.034) to develop PNALD for every day over 30 days in duration of their PN course. Infants who received $>3 \mathrm{~g} / \mathrm{kg} /$ day protein intake were less likely to develop PNALD (O.R. 0.61; C.I 0.396 - 0.932); whereas every increase in GIR $(\mathrm{mg} / \mathrm{kg} / \mathrm{min})$ was associated with a higher incidence of PNALD (O.R. 1.11; C.I 1.023 - 1.211).

\section{Discussion}

There have been several studies evaluating PNALD and the role of ILEs have played in its development, but few with a similar number of patients as ours, almost 350 and over such a long span, 7 years. We were able to confirm in a large cohort of infants with similar clinical conditions that other investigators had demonstrated as clinical conditions increasing the likelihood of PNALD [2] [4] [5]. Occurrence of sepsis, GI diagnosis as a PN indication, primarily NEC with bowel resection placed the infant at significantly increased risk versus those that did not experience these conditions [6] [25] [26]. A younger gestational age placed the infant at a significant risk of developing PNALD compared to those closer to term birth. Though, when analyzing size-for-gestational age, there was no significant difference between those who were small-for-gestational age ver- 
sus those who were not. Infants with PNALD had significantly lower birth weight compared to those who did not, which led to significantly longer hospital courses shown in the PNALD patients. Our Level IV neonatal intensive care unit (NICU) is a major gastrointestinal surgery referral center for the region. It is possible our incidence of PNALD may be skewed compared to other institutions, which mostly have term infants in their nurseries. Our cohort was predominantly African-American, which reflects the population of the city in which our institution is located.

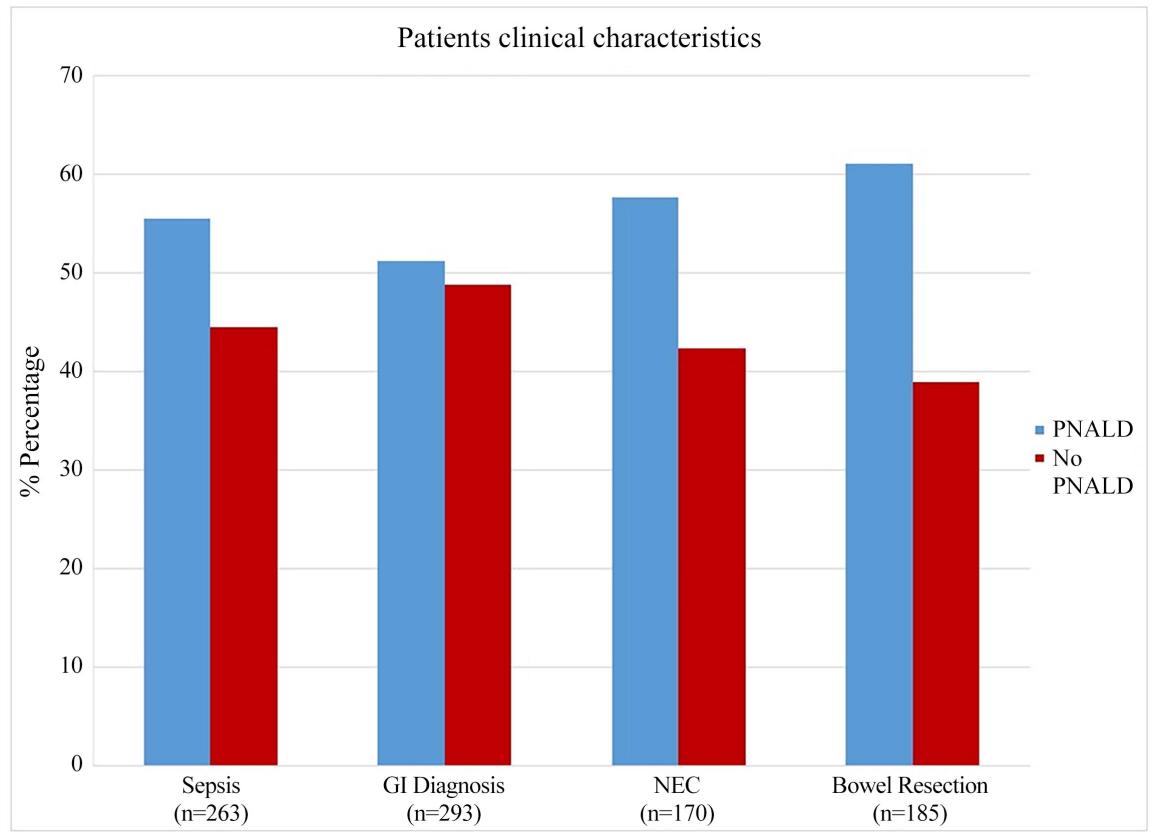

Figure 2. Common clinical characteristics among patients with or without Parenteral Nutrition Associated Liver Disease (PNALD). GI = Gastrointestinal Disease; NEC $=\mathrm{Ne}-$ crotizing Enterocolitis.

Table 1. Baseline patient demographics.

\begin{tabular}{cccc}
\hline & PNALD $(\mathbf{n}=149)$ & No PNALD $(\mathbf{n}=200)$ & p-value \\
\hline Gender- & & & \\
Female no. (\%) & $78(52.3)$ & $112(56)$ & NS \\
Male no. (\%) & $71(47.7)$ & $88(44)$ & \\
Race/Ethnicity - no. (\%) & & & \\
African American & $92(61.7)$ & $117(58.5)$ & NS \\
Caucasian & $42(28.2)$ & $70(35)$ & \\
Hispanic & $10(6.7)$ & $8(4)$ & 0.025 \\
Other & $5(3.4)$ & $5(2.5)$ & NS \\
Gestational Age (weeks) & $27(23-40)$ & $29.5(23-40)$ & 0.006 \\
Small-for-Gestational Age-no. (\%) & $42(28)$ & $49(24.5)$ & $<0.001$ \\
Birth weight (g) & $900(330-5648)$ & $1248(420-5448)$ & \\
Length of stay (days) & $126(34-463)$ & $79.5(32-492)$ &
\end{tabular}

NS $=$ not significant; PNALD $=$ Parenteral Nutrition Associated Liver Disease. Categorical data are expressed as total cases (percent). Continuous data are expressed as median (range). 
Table 2. Parenteral Nutrition (PN) and Feeding Characteristics.

\begin{tabular}{cccc}
\hline & PNALD $(\mathrm{n}=149)$ & No PNALD $(\mathrm{n}=200)$ & p-value \\
\hline Age PN initiated (days) & $7(0-135)$ & $2(0-358)$ & $<0.001$ \\
Duration of PN (days) & $80(30-386)$ & $44(30-313)$ & $<0.001$ \\
Age PN discontinued (days)* & $89(36-400)$ & $52.5(31-403)$ & $<0.001$ \\
NPO duration (days) & $17(0-106)$ & $14(0-61)$ & 0.003 \\
Age enteral feed initiation (days) & $30(1-98)$ & $20(1-137)$ & 0.001 \\
Age consistently fed (days) & $77(16-343)$ & $43(5-354)$ & $<0.001$ \\
\hline
\end{tabular}

${ }^{*}$ or age at discharged from facility or last observation (1/31/17). NPO = nil-per-os; PNALD = Parenteral Nutrition Associated Liver Disease. Data are expressed as median (range).

Table 3. Macronutrient Intakes between groups.

\begin{tabular}{|c|c|c|c|}
\hline & PNALD $(n=149)$ & No PNALD $(n=200)$ & p-value \\
\hline \multicolumn{4}{|l|}{ Protein } \\
\hline $\mathrm{AA}>3 \mathrm{~g} / \mathrm{kg} /$ day & $68(45.6 \%)$ & $116(58 \%)$ & 0.022 \\
\hline AA dose (g/kg/day) & $3(1.3-4.1)$ & $3.3(1-4.1)$ & 0.014 \\
\hline \multicolumn{4}{|l|}{ Dextrose } \\
\hline GIR $>14 \mathrm{mg} / \mathrm{kg} / \mathrm{min}$ & $18(12 \%)$ & $14(7 \%)$ & NS \\
\hline Mean GIR, mg/kg/min (SD) & $11.4(2.7)$ & $10.7(2.5)$ & 0.012 \\
\hline \multicolumn{4}{|l|}{ Lipids } \\
\hline ILE $>2 \mathrm{~g} / \mathrm{kg} /$ day & $104(69.8 \%)$ & $125(62.5 \%)$ & NS \\
\hline ILE dose (g/kg/day) & $2.9(0-3.2)$ & $2.7(0-3.2)$ & NS \\
\hline
\end{tabular}

AA = amino acid; GIR = glucose infusion rate; ILE = injectable lipid emulsion; NS = not significant; PNALD = Parenteral Nutrition Associated Liver Disease. Categorical data are expressed as total cases (percent). Continuous data are expressed as median (range) unless otherwise specified.

When evaluating our infants' feeding status, it was shown that infants who developed PNALD were NPO for a significantly longer duration. This in turn led to an almost doubling of the duration of PN for infants with PNALD. These infants were significantly older than the non-PNALD patients when they began PN, which may have not impacted the incidence of PNALD either way since they were on PN longer and were discontinued from PN at a later age. We looked at feeding characteristics in our cohort since it is the intervention with the best-proven benefit. Infants without PNALD began enteral feedings earlier and, achieved consistent intake at a significantly younger age compared to those who developed PNALD. This could have been a factor in the reduced length of stay for the non-PNALD patients as discussed before. Our group was particularly interested in knowing whether over-supplementation of a specific macronutrient had an effect on the development of PNALD. Other research groups have shown deleterious effects of particular macronutrients in the optimal liver function of preterm infants with lipid emulsions taking most of the negative spotlight in recent years [12] [27]. Some of these findings may not be valid anymore as some of the effects were attributed to composition and/or source of certain components which certainly have changed over the years. We found that intakes of soybean-based lipid emulsion were not statistically different between our in- 
fants that developed PNALD and those who did not. Non-PNALD patients received slightly higher-protein doses per day and received slightly lower glucose infusion rates than those who developed PNALD. PNALD infants were more likely to have been septic, reason why perhaps more restricted in certain aspects of their PN, as opposed to the healthier infants. These differences were statistically significant but whether they are clinically significant remains unclear. Once patients were discharged or transferred to another facility, we were unable to follow up on whether or not PNALD had resolved. The annual incidence of PNALD had fluctuations that could be explained by changes in practice occurring over the years. In 2009, there was a concerted effort by our neonatology, surgery and gastroenterology groups in standardizing both the initiation and advancement of enteral feedings in our patients, which led to the creation of feeding guidelines [19]. There was a learning curve to allow all our providers to become familiar with them; therefore, the effects of this intervention may not have affected the incidence of PNALD until 2011 [28]. In 2013, there was a similar revision in the feeding guidelines of patients with simple gastroschisis, which were included in this cohort that could have positively influenced the development of PNALD [29]. Also, during the study period, our practice site experienced 2 lipid shortages in 2010 and 2013, in which a lipid restriction protocol was implemented. This protocol restricted administration of lipids to three times or five times per week depending on the weight of the infant. This may have led to a period of protection from maximal doses of soybean-based lipid emulsion intake in those infants, affecting the development of PNALD [30]. Other institutions have reported positive outcomes for infants with PNALD on lipid-restricted regimens [21] [31].

A few limitations in our study that warrant discussion include the limits for age and peaks for the laboratory values that may have extended beyond our study period. In particular, for the infants that continued on PN after hospital discharge or our last day of analysis, 1/31/17. Their age of PN discontinuation and their duration of PN may have well extended beyond our study period and may not reflect an actual cessation of PN. The peaks reported may not be the actual ones over the course of their disease, only during our study period. The main limitation was the minimum PN duration of 30 days, likely excluding patients developing PNALD sooner than that. Previous studies have used an inclusion criterion of 14 days [25]. In that scenario, the infant is likely to be started on enteral nutrition, or advanced perhaps more aggressively, if already being fed, and PN can be weaned off shortly after. We chose 30 days as a surrogate for PN dependence. In these instances, even after developing PNALD, their GI condition and small volume of enteral feedings may not allow for PN to be discontinued. We consider this particular group of patients the one we should focus our efforts on. For now, clinicians can only be reactive when taking care of infants with PNALD such as starting trophic feedings sooner and/or initiating choleretic medications when possible. More research is needed to guide clinicians on the interventions needed. Our data suggests that protein intake and GIR may carry a 
bigger effect on development of PNALD than lipids intake. New ILEs available are definitely changing the landscape of PNALD that can reduce morbidity in these infants. The next step for us will be to evaluate use of a newer ILE and how it can prevent further progression of PNALD in our cohort and/or resolution as others research groups have seen.

\section{Conclusion}

Almost half of the infants who received parenteral nutrition for at least thirty consecutive days developed PNALD. Clinical factors associated with PNALD, coinciding with previous literature, included lower gestational age, lower birth weight, longer length of stay, sepsis, GI diagnosis, NEC, bowel resection, and older age at enteral feed initiation and at goal feeds. There were no statistically significant differences observed in lipid intake among those infants with PNALD versus those without. With the advent of new lipid emulsions entering the U.S. market, SMOFlipid ${ }^{\oplus}$ to name one, and its pending approval in children we will be interested in seeing how its use could affect our incidence of PNALD moving forward.

\section{Acknowledgements}

The authors acknowledge the contributions of Curtis Petty, Pharm.D. in obtaining access to the list of patients, as well as David Skinner, Pharm.D. and Amy Metcalfe, Pharm.D. for their assistance with data collection. L.H. Stuart was a clinical pharmacist at Le Bonheur Children's Hospital at the time when the project began, now she works at Children's of Mississippi.

\section{Conflicts of Interest}

M.L. Christensen is a member of Fresenius Kabi Data and Safety Monitoring Board. All other authors declare no conflicts of interest regarding the publication of this article.

\section{References}

[1] Ziegler, E.E., Thureen, P.J. and Carlson, S.J. (2002) Aggressive Nutrition of the Very Low Birthweight Infant. Clinics in Perinatology, 29, 225-244. https://doi.org/10.1016/S0095-5108(02)00007-6

[2] Drongowski, R.A. and Coran, A.G. (1989) An Analysis of Factors Contributing to the Development of Total Parenteral Nutrition-Induced Cholestasis. Journal of Parenteral and Enteral Nutrition, 13, 586-589. https://doi.org/10.1177/0148607189013006586

[3] Xu, Z.W. and Li, Y.S. (2012) Pathogenesis and Treatment of Parenteral Nutrition-Associated Liver Disease. Hepatobiliary \& Pancreatic Diseases International, 11, 586-593. https://doi.org/10.1016/S1499-3872(12)60229-X

[4] Christensen, R.D., Henry, E., Wiedmeier, S.E., Burnett, J. and Lambert, D.K. (2007) Identifying Patients, on the First Day of Life, at High-Risk of Developing Parenteral Nutrition-Associated Liver Disease. Journal of Perinatology, 27, 284-290. https://doi.org/10.1038/sj.jp.7211686 
[5] Willis, T.C., Carter, B.A., Rogers, S.P., Hawthorne, K.M., Hicks, P.D. and Abrams, S.A. (2010) High Rates of Mortality and Morbidity Occur in Infants with Parenteral Nutrition-Associated Cholestasis. Journal of Parenteral and Enteral Nutrition, 34, 32-37. https://doi.org/10.1177/0148607109332772

[6] Duro, D., Mitchell, P.D., Kalish, L.A., et al. (2011) Risk Factors for Parenteral Nutrition-Associated Liver Disease Following Surgical Therapy for Necrotizing Enterocolitis: A Glaser Pediatric Research Network Study [Corrected]. Journal of Pediatric Gastroenterology and Nutrition, 52, 595-600.

[7] Steinbach, M., Clark, R.H., Kelleher, A.S., et al. (2008) Demographic and Nutritional Factors Associated with Prolonged Cholestatic Jaundice in the Premature Infant. Journal of Perinatology, 28, 129-135. https://doi.org/10.1038/sj.jp.7211889

[8] Shin, J.I., Namgung, R., Park, M.S. and Lee, C. (2008) Could Lipid Infusion Be a Risk for Parenteral Nutrition-Associated Cholestasis in Low Birth Weight Neonates? European Journal of Pediatrics, 167, 197-202.

https://doi.org/10.1007/s00431-007-0454-7

[9] Koseesirikul, P., Chotinaruemol, S. and Ukarapol, N. (2012) Incidence and Risk Factors of Parenteral Nutrition-Associated Liver Disease in Newborn Infants. Pediatrics International, 54, 434-436. https://doi.org/10.1111/j.1442-200X.2012.03627.x

[10] Beckh, K., Kneip, S. and Arnold, R. (1994) Direct Regulation of Bile Secretion by Prostaglandins in Perfused Rat Liver. Hepatology, 19, 1208-1213. https://doi.org/10.1002/hep.1840190519

[11] Zaman, N., Tam, Y.K., Jewell, L.D. and Coutts, R.T. (1997) Effects of Intravenous Lipid as a Source of Energy in Parenteral Nutrition Associated Hepatic Dysfunction and Lidocaine Elimination: A Study Using Isolated Rat Liver Perfusion. Biopharmaceutics \& Drug Disposition, 18, 803-819. https://doi.org/10.1002/(SICI)1099-081X(199712)18:9\%3C803::AID-BDD65\%3E3.0. $\underline{\mathrm{CO} ; 2-\mathrm{S}}$

[12] Teng, J., Arnell, H., Bohlin, K., Nemeth, A. and Fischler, B. (2015) Impact of Parenteral Fat Composition on Cholestasis in Preterm Infants. Journal of Pediatric Gastroenterology and Nutrition, 60, 702-707. https://doi.org/10.1097/MPG.0000000000000739

[13] Pupillo, D., Correani, A., Biagetti, C., et al. (2018) Half-Life of Plasma Phytosterols in Very Low Birth Weight Preterm Infants on Routine Parenteral Nutrition with Vegetable Oil-Based Lipid Emulsions. Clinical Nutrition, 37, 262-269. https://doi.org/10.1016/j.clnu.2016.12.022

[14] El Kasmi, K.C., Anderson, A.L., Devereaux, M.W., et al. (2013) Phytosterols Promote Liver Injury and Kupffer Cell Activation in Parenteral Nutrition-Associated Liver Disease. Science Translational Medicine, 5, $206 \mathrm{ra} 137$. https://doi.org/10.1126/scitranslmed.3006898

[15] Teitelbaum, D.H., Han-Markey, T. and Schumacher, R.E. (1995) Treatment of Parenteral Nutrition-Associated Cholestasis with Cholecystokinin-Octapeptide. Journal of Pediatric Surgery, 30, 1082-1085. https://doi.org/10.1016/0022-3468(95)90346-1

[16] Chen, C.Y., Tsao, P.N., Chen, H.L., Chou, H.C., Hsieh, W.S. and Chang, M.H. (2004) Ursodeoxycholic Acid (UDCA) Therapy in Very-Low-Birth-Weight Infants with Parenteral Nutrition-Associated Cholestasis. The Journal of Pediatrics, 145, 317-321. https://doi.org/10.1016/j.jpeds.2004.05.038

[17] Rollins, M.D., Scaife, E.R., Jackson, W.D., Meyers, R.L., Mulroy, C.W. and Book, 
L.S. (2010) Elimination of Soybean Lipid Emulsion in Parenteral Nutrition and Supplementation with Enteral Fish Oil Improve Cholestasis in Infants with Short Bowel Syndrome. Nutrition in Clinical Practice, 25, 199-204. https://doi.org/10.1177/0884533610361477

[18] Tillman, E.M., Crill, C.M., Black, D.D., et al. (2011) Enteral Fish Oil for Treatment of Parenteral Nutrition-Associated Liver Disease in Six Infants with Short-Bowel Syndrome. Pharmacotherapy, 31, 503-509. https://doi.org/10.1592/phco.31.5.503

[19] Tillman, E.M., Norman, J.L., Huang, E.Y., Lazar, L.F. and Crill, C.M. (2014) Evaluation of Parenteral Nutrition-Associated Liver Disease in Infants with Necrotizing Enterocolitis Before and after the Implementation of Feeding Guidelines. Nutrition in Clinical Practice, 29, 234-237. https://doi.org/10.1177/0884533614522834

[20] Jensen, A.R., Goldin, A.B., Koopmeiners, J.S., Stevens, J., Waldhausen, J.H. and Kim, S.S. (2009) The Association of Cyclic Parenteral Nutrition and Decreased Incidence of Cholestatic Liver Disease in Patients with Gastroschisis. Journal of Pediatric Surgery, 44, 183-189. https://doi.org/10.1016/j.jpedsurg.2008.10.033

[21] Cober, M.P., Killu, G., Brattain, A., Welch, K.B., Kunisaki, S.M. and Teitelbaum, D.H. (2012) Intravenous Fat Emulsions Reduction for Patients with Parenteral Nutrition-Associated Liver Disease. The Journal of pediatrics, 160, 421-427.

https://doi.org/10.1016/j.jpeds.2011.08.047

[22] Puder, M., Valim, C., Meisel, J.A., et al. (2009) Parenteral Fish Oil Improves Outcomes in Patients with Parenteral Nutrition-Associated Liver Injury. Annals of Surgery, 250, 395-402.

[23] Diamond, I.R., Grant, R.C., Pencharz, P.B., et al. (2017) Preventing the Progression of Intestinal Failure-Associated Liver Disease in Infants Using a Composite Lipid Emulsion: A Pilot Randomized Controlled Trial of SMOFlipid. Journal of Parenteral and Enteral Nutrition, 41, 866-877. https://doi.org/10.1177/0148607115626921

[24] Wales, P.W., Allen, N., Worthington, P., et al. (2014) A.S.P.E.N. Clinical Guidelines: Support of Pediatric Patients with Intestinal Failure at Risk of Parenteral Nutrition-Associated Liver Disease. Journal of Parenteral and Enteral Nutrition, 38, 538-557. https://doi.org/10.1177/0148607114527772

[25] Hsieh, M.H., Pai, W., Tseng, H.I., Yang, S.N., Lu, C.C. and Chen, H.L. (2009) Parenteral Nutrition-Associated Cholestasis in Premature Babies: Risk Factors and Predictors. Pediatrics and Neonatology, 50, 202-207.

https://doi.org/10.1016/S1875-9572(09)60064-4

[26] Robinson, D.T. and Ehrenkranz, R.A. (2008) Parenteral Nutrition-Associated Cholestasis in Small for Gestational Age Infants. The Journal of Pediatrics, 152, 59-62. https://doi.org/10.1016/j.jpeds.2007.06.002

[27] Brown, M.R., Thunberg, B.J., Golub, L., Maniscalco, W.M., Cox, C. and Shapiro, D.L. (1989) Decreased Cholestasis with Enteral Instead of Intravenous Protein in the Very Low-Birth-Weight Infant. Journal of Pediatric Gastroenterology and $\mathrm{Nu}$ trition, 9, 21-27. https://doi.org/10.1097/00005176-198909010-00005

[28] Savoie, K.B., Bachier-Rodriguez, M., Jones, T.L., et al. (2016) Standardization of Feeding Advancement after Neonatal Gastrointestinal Surgery: Does It Improve Outcomes? Nutrition in Clinical Practice, 31, 810-818. https://doi.org/10.1177/0884533616658766

[29] Passaro, R.C., Savoie, K.B. and Huang, E.Y. (2018) Use of a Gastroschisis Feeding Guideline to Improve Standardization of Care and Patient Outcomes at an Urban Children's Hospital. Nutrition in Clinical Practice, 33, 545-552.

[30] Cober, M.P. and Teitelbaum, D.H. (2010) Prevention of Parenteral Nutri- 
tion-Associated Liver Disease: Lipid Minimization. Current Opinion in Organ Transplantation, 15, 330-333. https://doi.org/10.1097/MOT.0b013e328338c2da

[31] Calkins, K.L., Havranek, T., Kelley-Quon, L.I., et al. (2017) Low-Dose Parenteral Soybean Oil for the Prevention of Parenteral Nutrition-Associated Liver Disease in Neonates with Gastrointestinal Disorders. Journal of Parenteral and Enteral Nutrition, 41, 404-411. https://doi.org/10.1177/0148607115588334 